\title{
Transformative Teacher Education in the Community of Knowledge ${ }^{1}$
}

\section{Dr. Taher Mohammad Al-Hadi} Professor of Curriculum and EFL Instruction

Faculty of Education, Suez Canal University

\section{Abstract :}

Deacher education aims to foster a change in perspective in teaching and learning within various educational contexts from prospective teachers to real teachers. This change is often seen to involve three forms of knowing: knowing "that", knowing "how", and knowing "why". Transformative learning has much to do with such a change. When prospective teachers critically reflect on teaching as a process, and are engaged in a rational dialogue within a safe, supportive, collaborative classroom environment, they will be able to accomplish the outcomes coming and then consider them in future practices: elaborating or redefining the existing frames of reference, learning new frames of reference, transforming points of views, and transforming habits of mind. By so doing, they can become transformative teachers who can affect their learners - implicitly or explicitly - to be transformative as well.Therefore, this paper addresses how transformative learning can be activated in teacher education programs in general for constructing a community of knowledge. The paper has four main sections. Section one deals with the relationship between transformative learning, critical reflection and teacher education. Section two tackles the form, the features and the requirements of the pedagogic context for developing transformative learning. The paper concludes with section three which proposes a conceptual model for using transformative

1 Paper Presented to the 3rd International Conference (The Future of Teacher's Preparation and Qualification in the Arab World) in Faculty of Education (October 6th University) 23 - 24 April 2017 
learning in teacher education contexts. It ends with section four giving some implications that can be implemented so as to set the proposed transformative learning-based model into practice.

Key words: Transformative Teacher Education, Community of Knowledge.

\section{Introduction}

Any teacher education program is confronted by a myriad of contextual considerations ranging from student's social, cultural and linguistic backgrounds to multi-memberships and community economic, political, social and cultural changes. Preparation for effective teaching in such settings requires much more than learning to apply technical, research-based knowledge. Prospective teachers - especially EFLers - are in need to critically reflect on the crucial issues and problems different educational settings may present and their possible consequences; consider alternative perspectives in different contexts and rethink of their past practices and experiences and those of others; and above all practice transformative learning.

How then are these practices take place in teacher education programs. Many reform efforts have been increased with new labels that are attached to familiar practices. In their Teacher Education and the Social Traditions of Schooling, Listen \& Zeichner cited in Zeichner (1993) describe four traditions of practice: (1) "an academic tradition which emphasizes teachers' knowledge of subject matter and general education." It is a matter of apprenticeship experience in which trainees learn by imitating the experts' techniques and following their instructions and advice, (2) "a social efficiency tradition which emphasizes teachers' abilities to apply a 'knowledge-base' about teaching that has been generated through research on teaching. " From such a perspective, competency/performance-Based Teacher Education (C/CBTE) emerged emphasizing the acquisition of specific and observable skills of teaching which are assumed to be related to student learning," (3) "a developmentalist tradition which stresses teachers' abilities to base their instruction on their direct knowledge of their students' current understandings 
of the content under study, and their developmental readiness for and/or interest in particular activities, and (4) a social reconstuctionist tradition which emphasizes teachers' abilities to see the social and political implications of their actions and to assess their actions and the social contexts in which they are carried out for their contribution to greater justice, and more humane conditions in schooling and society, (p. 7)."

"One of the main goals of a teacher education program should be to produce graduates who have a deep understanding of teaching and learning and who can use these insights in their future practices, Darling. Hammand cited in Hoban (2000: p. 165)." Therefore, the authoritarian approach to teacher education, characterized by expert-driven, didactic teaching with its emphasis on rote learning and technical skills, is no longer wholly appropriate because it undermines learner autonomy. A more reflective and analytical approach, in contrast, is likely to better accommodate self-direction and lifelong learning and be more compatible with the recommendations given by the Supreme Council of Universities in Egypt, and with the research evidence about learning, motivation, and meaningful professional development. A culture change might help create the conditions of trust and openness to make the transformative learning function optimally. It might encourage students (EFL prospective teachers in this context) to feel free to share their problems and express their learning needs. Such an approach would build in development of professional characteristics rather than these of the technician. At the same time, the classroom - as Chudhuri (2007: p. 93) thinks - should be "a place where there is a sense of struggle in forming relationships ... Where we work together as teachers and students to overcome the estrangement and alienation that have become so much the norm in the contemporary university." In the same line of thought, Lucas \& Tan (2006) stress that "within undergraduate education, there is an increasing emphasis on the need for reflection as an integral part of learning to lean. We expect students to reflect as a part of their subject-based studies, but also to reflect on their learning and development of skills, (p. 3)." 
This means that in order to become an effective member of the work place of the future, essential understandings, skills and dispositions are required. When the adult learner is equipped with some key competencies such as analyzing information, communicating ideas, planning and organizing activities, using technology, working in teams, solving problems, and using cultural under standings, he can become a productive and responsible individual for the twenty first century.

Higher education is seen by Gliscziniski (2007) as having the potential to saw the seeds of conscientization, understanding, insight and transformation by fostering proactive thinking, incorporating multiple perspectives, and encouraging dialog and construction of knowledge. Such a view indicate two things: (1) students vary in their capacity to reflect and to exercise judgment according to different beliefs about knowledge or their "ways of knowledge" as expressed by Magolda cited in Lucas \& Tan (2006); and (2) adults are understood to be active engaged participants in the learning process, co-creating or constructing what it is they are learning as they learn, Dirkx (2009).

In today's postmodern world, perspective, empathy and self-knowledge suggested by Wiggins and McTighe cited in Gliscziniski (2007) must be there in higher education - which "require learners to analyze information from a variety of perspectives, explain other people's experiences, and act on their learning in their own lives, (p. 318)." But within the educational institutions that should do that job, "critically reflective discourse is largely absent" in America for example, though it spends much effort pursuing cultural capital and human capital (Gliscziniski, 2007). If this is the case with the United States with its wealth of information and resources, the situation in Egypt might not be the same.

During the last decades, there have been claims for educational reform in Egypt. Social changes are among the forces that have pressure on the educational system to adopt new approaches in adult education which might respond to the new requirements of the society. And because of having the most 
important facet of the educational reform might be the reformation of teacher education program, the various contributions of the transformative learning theory (TLT) would highlight the way to the change and the reformation of teacher education programs specifically the EFL one.

\section{Transformative Learning and Critical Reflection}

Although it is difficult to put demarcation lines between transformative learning, critical reflection and adult education, the following is a suggested outline of the different aspects of each and the integrators within each. Within the global view of learning, Cranton cited in Dirkx (2009) holds a strong view that "learning is not simply a preparation for life. It is life, the experience of living. Coming to know ourselves in the world and how we make sense of the other within this world are critical aspects of learning." By this, it is assumed that learners are human beings who are formed and form themselves within some limited perspective. Events, relationships, forces or influences shape their experiences and perceptions. Such practices stimulate the responsibility of teacher education programs to help learners learn how to learn to understand problems, to work with other people in this process, to challenge another's thinking about related topics, and to gain self-insight. The role of educators then becomes - according to Mezirow (2000) - to:

- help the learner focus on and examine the assumptions that underlie his beliefs, feelings and actions.

- assess the consequence of these assumptions, test the validity of assumptions through effective participation in reflective dialog.

For such reasons, Mezizow $(1990,1998,2000)$ sets three types of learning according to the interactional discourse: instrumental communicative and emancipatory, while Miller \& Seller cited in MeGregor (2008) provide other three types but related to the orientations to curriculum: transmissional, transactional, and transformational, which differ on several dimensions: control and sharing of power, what counts as 
legitimate knowledge and how meaning should be constructed, the intended learning outcome, and attendant pedagogical approach. Mezirow cited in Wikipedia (2009) posits that all learning is change but not all change is transformation. He differentiates between the later types of education. In transmissional learning, knowledge is transmitted from teacher to student; in the transactional, it is recognized that the student has valuable experiences and learn best through experience, inquiry, critical thinking and interaction with other learners. And learning is transformative when it involves the transformation of frames of reference: points of view, habits of mind and world views, (Holistic Education Network, 2005). Learning - thus - is not seen as simply acquiring new knowledge or skills. It is - as Daugherity (2008) sees " a matter of changing one's identity ... one is a new person because she has experienced a new meaning, or a new perspective on previous understandings, (p. 4)."

\section{Adult Education:}

Adult education is an umbrella term that covers different education programs including teacher education. Therefore, adult education and teacher education might be used interchangeably. Adults are assumed to be naturally in a developmental stage of life when they are involved in programs that focus on the personal experiences and perspectives of youth, creating circumstances for challenging their views and values. Such a period is an ideal time for challenging the moral and ethical convictions of young people, and helping them to expand their universe of responsibility. When Mezirow (1997) identifies the four processes of learning (to elaborate an existing point of view, to establish new points of view, to transform our point of view, and to become aware and critically reflective of our generalized bias related to the existing point of view), he is believed to revolve round the most significant perspective transmission: knowledge transmission. The challenge in teaching contexts addresses which type of knowledge is to be learned, tested, then transformed. In teacher education as a form of adult education, the process of learning reflects on the limits of 
knowledge, the certainty of knowledge, and the criteria for knowing. From qualitative approach, Magalda cited in Lucas and Tan (2006: pp. 4-5) mentions four different ways of knowing. They are:

- Absolute knowing: knowledge exists in an absolute form, it is either right or wrong.

- Transitional knowing: knowledge is certain in some areas and uncertain in other areas.

- Independent knowing: knowledge is uncertain, Everyone has their own beliefs.

- Contextual knowing: knowledge is contextual. One judges on the basis of evidence in context."

- From a different lens, Belenky and Stanton (2009) classify knowledge according to the capacities of participants of meaning-making frameworks.

- Silenced knowers are those who may see themselves learning from their own concrete actions, but do not believe themselves capable of learning from experiences mediated by language. Unable to give words to what they know, these people think of themselves as voiceless. They also find it difficult to acquire new understandings by listening to what others have to say.

- Received knowers are people characterized by a learning style consisting of listening to others (authorities, experts) and remembering what they have to say.

- Subjective knowers are characterized as people who are aware that they themselves can think up ideas of their own, listen to their own inner voice, articulate their own thoughts and criticize their former dependence on authorities for knowledge and direction.

- Separate knowers work towards critiquing what they hear or read; they tend towards assessing intentions behind the words; the coherence, verocity and appropriateness of what is being communicated. This requires critical reflection on the part of the separate 
knower and the ability to arrive at understanding through rational discourse. The objective of evaluating various options through dialog and discourse is to achieve consensus for the best choice.

- Connected knowers look for strengths not weaknesses, in another's argument. They actually try to enter into another's perspective, adopting their frames of mind, trying to see the world through their eyes.

- Constructivist knowers provide a perspective for people whom see themselves, and everyone also, as coconstructors of knowledge. They actively cultivate the whole range of approach. They learn from concrete experience as with the silenced; they learn by listing to others as with received knowers; they learn from experience, intuition, feelings and insights as well as with subjective knowers; and they learn from both the separate and connected approaches to procedural knowing. They stand back, question, take a part, and criticize points views they see as partial, unfair, and/or destructive. They also move inward, see the whole, listen, understand, integrate, build up, and create.

\section{Transformative Learning, Overview:}

Departing from the premise that the goal of adult education is implied by the nature of adult learning and communication - to help the individual become a more autonomous thinker by learning to negotiate his or her own values, meanings and purposes rather than to uncritically act on those of others, transformative learning becomes the essence of adult education. And because "transformation and change are part of human life as multifaceted ongoing phenomena (Trouverso-types, 2008: p. 157)," a shift in beliefs, deep self-reflection and a discourse of that reflection are required to have a certain level of development and cognitive maturity. This is why transformative learning theory is strongly connected with adult learning.

According to TLT, " learning is understood as the process of using a prior interpretation to construe a new or revised 
interpretation of the meaning of one's experience in order to guide future action, Mezirow cited in Feldt (2006: p. 5). Such a process might be of becoming aware of one's assumptions and revising these assumptions. If basic assumptions are not challenged, change will not take place. Cranton cited in Nelson (2007) presents a framework of three types of change: change in assumptions, change in perspective, and change in behavior. That process - in Mezirow's belief cited Holistic Education Network (2005) extends to include the assumptions of others and their content. He argues that "transformation theory's focus is on how we learn to negotiate and act on our own purposes, values, feelings and meanings, rather than those we have uncritically assimilated from others - to gain greater control over our lives as socially responsible, clear thinking decision-makers.

In a similar line of thought, Donovan et al. (2007) argues that transformation includes cognitive, emotional, and social components of knowledge and behavioral change. At the cognitive level, learning needs to be integral to change, at an emotional level, transformation may elicit a range of reactions such as empathy, encouragement self-efficacy fear, or hopelessness. At social levels, transformation may be instrumental in fostering stronger social relationship or bringing about misunderstanding or conflict. If transformative learning does not cause change, it may lead at least - to move experiences forward, i.e. "to open up frame of reference, discard a habit of mind, see alternatives and thereby act differently in the world, Mezirew and associates cited in Cranton \& King (2003: p. 32). Gardner (2008) calls such process the pedagogy of. And because movement. Bearing in mind that movement is an important metaphor of today's twenty-first century educational landscape and movement - to Gardner - is an invaluable pedagogical lens because it reflects teacher and learners complex experiences, a pedagogy of movement invites educators and learners into a large conversation that engages this lens through their own " moving" experiences and practices, (pp. 27-28)." 
To Hallet et al. (2009), transformative learning takes a pragmatic perspective. When universities integrate servicelearning (i.e., serving the needs and addressing the problem of the community) into their general education requirements and students are engaged in real-world settings, and given opportunities in life-changing experiences, community-based transformational learning (CBTL) becomes an ideal opportunity for distinction. Academic excellence and student learning will be enhanced; relevance will be promoted; the accountability will be strengthened, in addition to the increase of civic awareness. If the CBTL rests on the assumption that student learning is based on the application of knowledge through active involvement and engagement in relevant authentic learning activities, as well as extra - and co-curricular opportunities and activities, such significant learning experiences as labeled by Fink cited in Hallet et al. (2009) becomes deep and durable. Consequently, transformation takes place. That notion is stressed by Hallet et al. stating: " If we conceptualize student learning as involving the retention of information and disciplinary knowledge, and the ability to transfer what is learned to new and different settings, it is clear that confining education to the memorization and recall of information is insufficient. That is - retention and transfer require not simply content knowledge but active participation in a process whereby that information and knowledge is used and applied, (p. 6)."

As a state, adults have acquired a coherent body of experience associations, concepts, values, feelings, conditioned responses - frames of reference that define their life world. Frames of reference are the structures of assumptions through which we understand our experience. They selectively shape and limit expectations, perceptions, cognition, and feelings. They set our "line of action." Once set, we automatically move from one specific activity (mental or behavioral) to another. We have a strong tendency to reject ideas that fail to fit our preconceptions ... When circumstances permit, transformative learners move 
toward a frame of reference that is more inclusive, discriminating, self-reflective, and integrative of experience, ( $p$. 5)."

Mezirow (op.cit.) states two dimensions of a frame of reference: habits of mind and a point of view. Habits of mind are broad, abstract, orienting, habitual ways of thinking, feeling, and acting influenced by assumptions that constitute a set of codes. These codes may be cultural, social, educational, economic, political or psychological. Habits of mind become articulated in a specific point of view - the constellation of belief, value judgment, attitude, and feeling that shapes a particular interpretation. Something important is given due attention, that is: habits of mind are more durable than points of view. Points of view are subject to continuing change as we reflect on either the content or process by which we solve problems and identify the need to modify assumptions. This happens whenever we try to understand actions that do not work the way we anticipated.

While Mezirow - throughout his work on TLT - discusses the important dilemma as a pre - requisite to transformative learning or a part of the transformative learning experience characterized by high levels of ambiguity, uncertainty and paradox, Dirkx (2009) introduces a new dimension of transformative learning. He stresses soulful learning through feeling, intuition and imagination seeking for self-knowledge or ego consciousness. This is because " the experience of soul [in teaching and learning] leads to an appreciation of the multiplicity of selves that make up who we are," (Brisken cited in Dirkx, 2009). Besides, viewing our experience through soul draws our attention to the quality of experiencing life and ourselves, to matters of depth, values, relatedness and heart. Soul to do with authenticity, connection between heart and mind, mind and emotion, the dark as well as the light. When attending to soul, we are seeking to live deeply, to focus on the concreteness of the here-and-now, Dirkx (2009).

In short, transformative learning is a process of becoming critically aware of one's own tacit assumptions and expectations 
and those of others and assessing their relevance for making an interaction, Mezirow (2000). This process requires change of frames of reference and consciously making and implementing plans that bring about new ways of defining worlds, i.e., opening to alternatives and consequently changing the way one sees things. Transformative learning involves experiencing a deep, structural shift in the basic premises of thought, feelings and actions.

It is claimed by Taylor (1998) that "there are ... a few people who have started to work more with this theory [TLT] and to develop it more and add new ideas, (p. 1)", although Jack Mezirow considers it to be based off of a careful integration of theories - mainly the psycho analytic theory, the critical social theory and the constructivist theory-models and ideas from a wide variety of sources. Besides, it is widely developed and implemented in different contexts till it has become a feature of the twenty-first century. To the researcher's belief, many types of learning are reflected in TLT: instrumental learning that focuses on learning through task -oriented problem solving and determination of cause and effect relationships; communicative learning in which learning is involved with how others communicate their feelings, needs and desires with other person, emancipatory learning that helps learners reassess their experiences and more to new mindsets (Mezirow: 1998); soulful learning in which change cannot be achieved without being emotionally and psychologically ready for change (Dirkx: 2009); restorative learning in which the restoration of the participants, foundational ethics to a conscious place in the daily lives; relational learning that fasters relationships among practitioners, collaborating and exchanging views and building new mindsets acquiring new perspectives; assimilative learning that takes place when students simply acquire new information that can easily fit into their pre-existing knowledge structures; deep learning that goes beyond just content knowledge acquisition, or memorizing or learning facts and data. It is a process for adults to learn to think for themselves through true emancipation from unquestioning acceptance of what we have to come to know 
through our life experience. To conclude, no single model of transformative learning exists.

Many researchers (e.g. Dirkx, 2009; Erickson, 2007; Foster, 1997; Gardner, 2008; Jarvis et al., 2003; Kerka, 2007; Stein, 2008) even the initiator of TLT describe it as a constructivist theory of adult learning. And it extends from contemporary psycho-analytical, behavioristic and humanistic theories on how adults learn. It is a learning theory that is mainly centered on meaning-making. And Mezirow seeks to explain the way adult learning is structured and to determine by what processes the frames of reference through which we view and interpret our experiences are changed or transformed. In the researcher's belief, TLT is more than a constructivist theory. It is constructionist as well. Such a view is supported by van der Haar and Hosking cited in Donovan et al. (2007: p. 3). They make an important distinction between constructivism and constructionism.

The former is primarily an intra-cognitive activity of an individual inquirer who separates him/herself from his/her own discourse. In contrast, constructionism is socio-relational and focuses on attention on processes of relating, with the inquirer seen as a participant in the discourse that she is co-constructing." At the same time, the Information Transformation Learning Process considers the role of self in learning, (IATUL, 2009), i.e., in transforming and interpreting information and constructing meaning. "We must see knowledge as social construction that reflects the perspectives, values and experiences of the people and cultures that constructed it. Knowledge is not a static artifact, but a dynamic debate among its creators and users, (op. cit., p. 3)."

\section{Phases of Transformative Learning.}

Educators including Jack Mezirow differ in defining the phases of TL or what they are sometimes referred to the elements of Mezirow's TLT. Mezirow (1990) defines 10 phases: (1) a disorienting dilemma; (2) self-examination with feelings of guilt or shame; (3) a critical assessment of assumption; (4) recognition that one's discontent and process of transformation 
are shared and that others have negotiated a similar change; (5) exploration of options for new roles, relationships, and actions; (6) planning of a course of action; (7) acquisition of knowledge and skills for implementing one's plans; (8) previously trying out new roles; (9) building of competence and self-confidence in new roles and relationships; (10) a reintegration into one's life on the basis of conditions dictated by one's new perspective. Harbers (1998) condensed those ten phases of perspective transformation into four disorienting dilemmas, critical reflection, rational dialogue, and action - that are akin to Kolb's experiential learning cycle, which consists of cycles of concrete experiences, reflection, abstract conceptualization and active experimentation. In order to implement aspects of TLT, five elements - to Taylor (1998) should be considered: disorienting dilemma, meaning structures, reflective thinking, rational discourse, and context. Since transformative learning is a process that is featured by consciousness-raising among adults to foster critical perspective, critically reflecting on their experiences to perceive and understand themselves and the world they inhibit, and developing their ability to replace old ways of meaningmaking with one's that are more appropriate to the demands that adults encounter at specific points in their life, Merriam and Caforella cited in Wikipedia (2009) codify transformative learning into three phases including critical reflection, reflective discourse and action. These ways seem to go in parallel with the four ways suggested by Mezirow (2000) for transformations to come about: elaborating existing frames of reference, learning new frames of reference, transforming points of views, and transforming habits of the mind. Whatever the number of phases, there must be meaning schemes to be redefined or elaborated and/or new meaning schemes to be learned, and meaning schemes and/or meaning perspectives to be transformed to other people or to other situations.

\section{Why Transformative Learning:}

Transformative learning is best seen and should be the goal of adult education for more than one reason: (a) students have 
something to give back and something to contribute to the learning environment instead of memorizing and giving the information back, (Merriam \& Coffarella, 1999); (b) students move back and forth around their experiences and those of others in a critical way between reflecting and acting on the world, i.e., practicing critical reflection, (Taylor, 1998); (c) the horizontal student-teacher relationship creates an atmosphere that people feel comfortable to share and communicate in, (Taylor, 1998), and because any foreign language has something to offer to everyone regardless of the reason for study, (d) it is believed that achieving the five of foreign language education (communication, cultures, connections, comparisons and communities) referred to U.S. Department of Education and the National Endowment for the Humanities (2006) will lead to transformative learning, and consequently realize the standards for foreign language learning in the $21^{\text {st }}$ century. They state the issue as thus:

Communication, or communicating in languages other than English, is at the heart of second language study, whether the communication takes place face to face, in writing, or across centuries through the reading of literature. Through the study of other languages, students gain a knowledge and understanding of the cultures that use that language; in fact, students cannot truly master the language until they have also mastered the cultural contexts in which the language occurs. Learning languages provides connections to additional bodies of knowledge that are unavailable to monolingual English speakers. Through comparisons and contrasts with the language studied, students develop greater "insight into their own language and culture and realize that multiple ways of viewing the world exist. Together, these elements enable the student of languages to participate in multilingual communities at home and around the world in a variety of contents and in culturally appropriate ways, (p. 31)."

Transformative learning develops autonomous thinking. This means that we have to learn to think, to understand the 
meaning of our experience and learn to make our own interpretations rather than uncritically act on the purposes, beliefs, judgments, and feelings of others. Adult learners themselves - as Stain cited in Mezirow (1997: p. 8) asserts - view learning to think as autonomous, responsible persons as an educational objective who" (1) gain access to information as that they can orient themselves in the world; (2) give voice to their ideas, with the confidence they will be heard; (3) make decisions and act independently, and (4) build a bridge to the future by learning how to learn. "Besides, transformative learning is a possible and desirable outcome to the learning process, in which deep levels of understanding and reinterpretation of one's values are achieved, (Daughirity: 2008).

To Holistic education Network (2005), there are several reasons to consider transformative learning theory and practice for students (particularly adolescents) in school and collages.

- Transformative learning equips students with the concepts and understanding necessary to make a success to transition to adult life.

- When students are led to a deeper understanding of concepts and issues, their fundamental beliefs and assumptions may be challenged leading to a transformation of perspective or worldview.

- As we ask students to develop critical and reflective thinking skills and encourage them to care about the world around them, they may decide that some degree of personal or social transformation is required. Students will need the tools of transformative learning in order to be effective change agents.

We are living through a period of transformational change in society and culture. Students will be better able to understand and deal with such change if they understand the nature of 
transformation and the impact it has on individuals, groups, organizations and nations.

\section{Requirements of Transformative Learning.}

Those who (have) worked in transformation theory field depict certain ideals or conditions to foster transformative learning. Formal educational experiences can play a critical role in helping adults recognize the process of meaning making and construction, and learning as transformation. Such an idea implies considering the self's involvement in the learning process. A full understanding of one's personal experience depends on a deeper understanding of the social, political, and cultural context in which one lives. In order to foster transformative learning, we must understand the self of the learner in context, (Dirkx, 2009). In other words, having an experience is not enough to effect a transformation. What is valuable is not the experience itself but the intellectual growth that follows the process of reflecting on experience. Effective learning does not follow from a positive experience but from effective reflection. Thus, critical reflection is central to transformative learning especially adults.

Stressing that people construct their own meaning out of experiences, then they interpret their experiences versus universal and recognizable truths. The emphasis here is on creating new realities together. Adult learners - as it is known carry multiple identities and move across multiple communities and cultures. They - as a result participate in multiple communities of practice sharing frames of reference or developing shared frames of reference. Joining in some communities of practice through rational discourse practicing not just of presenting the world, but of signifying the world, constituting and constructing the world in meaning in Ronhalt's view cited in Erickson, 2007: p. 140) is of great importance in fostering transformative learning.

Morrison (2008) reports that transformative learning often requires a "structural shift" in the way thoughts, feelings, and actions are conceptualized. "This shift is at once conscious, 
dramatic, and lasting; and it holds an opportunity to change the way we are in the world. In order for any kind of shift to occur, there must be movement and struggle, (p.111).

" Transformation, which should be allowed to seep through our institutions and relationships, usually comes in small doses, and usually happens over time. This transformation is accomplished over time by building layers of confidence and selfcritique, (Doyle, 2008: p. 155). Even within organizational contexts with the hope of enhancing organizational effectiveness, Yorks \& Marsick (2009) implemented two strategies - Action learning and Collaborative Inquiry - for fostering learning from experience through cycles of action and subsequent reflection on that action. Their point of departure seems to be from the premise that adult learning is a socially interactive activity and often occurs in a group setting, and " teams, groups and networks can become the medium for moving new knowledge through the learning organization and that such collaborative structures enhance the organization ability to learn because they offer avenues for exchange of new ways of working.

This is why Yorks and Marsick consider the organizational learning as transformative learning. In the same line of through, Donovan et al. (2007) used the Appreciative Inquiry (AI) as a transformation strategy to cause enlightened deep organizational change stressing that $\mathrm{AI}$ and transformative learning can inform and support one another. In their view, that strategy has four phases. The Discover phase provides the context for individuals and groups to inquire together about successful experiences. Within the Dream phase, participants begin to challenge their previous assumptions, reframe expectations, co-create positive images and recognize their shared strengths and capacities. The Design phase fosters the exploration, options and the adoption of a new mindset consistent. With socio-technical systems. Finally, the Destiny phase comes in which opportunities for inquiry emerge, competence and confidence arise and new roles and relationships take place. 
It is worthy to note that there are other conditions and requirements equally important to those emphasized, and they will be tackled in section two of this paper.

\section{Critical Reflection.}

Reflective thinking is known to be a rational, deliberative process triggered by experience used for problem solving. It is viewed as a teaching strategy as well as a learning style. Besides, it is characterized by being closely related to situations of uncertainty and being an action-oriented process focusing on analyzing and assessing assumption. But it should be noted that not all reflection is critical. Critical reflection is considered to be the highest level of reflective thinking.

Critical reflection - in Mezirow's belief cited in Feldt (2006) - is the distinguishing characteristic of adult education. It " refers to questioning the integrity of assumptions and beliefs base on prior knowledge. It often occurs in response to an awareness of a contradiction among our thoughts, feelings, and actions, (p. 9)." To Brookfield cited in Stain (2008), critical reflection is an adult learning strategy of four processes. First, assumption analysis which describes the activity adults engage in to bring to awareness beliefs, values, cultural practices, and social structures regulating behavior and to assess their impact on daily activities, describes how relationships should be ordered, and then makes explicit our taken-for-granted notions of reality. Second, contextual awareness which is achieved when adult learners come to realize that their assumptions are socially and personally created in a specific historical and cultural context. Third, imaginative speculation that provides an opportunity for adults to challenge prevailing ways of knowing and acting by imagining alternative ways of thinking about phenomena. Fourth, the outcome of assumption analysis, contextual awareness and imaginative speculation is reflective skepticism the questioning of any universal truth claims or examined patterns of interaction. Critical reflection then addresses the question of the justification for the very premises on which problems are posed or defined in the first place. It is to validate 
the long-taken-for granted meaning perspective. It is not concerned with the how - to of action but with the why, the reasons for and consequences of what we do (Mezirow, 1990, p. 13)." Cranton cited in Nelson (2007) elaborates the idea and seems to be in agreement with Mezirow. He defines critical reflection as the means by which we work through beliefs and assumptions, assessing their validity in the light of new experiences or knowledge considering their sources, and examining underlying premises. The matter does not limit itself to just assess and validate the experiences, but extends to constructing knowledge. Critical reflection - then becomes the process by which adults identify the assumptions governing their actions, locate the historical and cultural origins of the assumptions, question the meaning of the assumptions, and develop alternative ways of acting ... Through the process of critical reflection, adults come to interpret and create new knowledge and actions from their ordinary and sometimes extraordinary experiences (Cranton cited in Stein 2008).

Critical reflection - to the research's belief - can be considered an approach to evaluating instructional effectiveness of opportunities given to students for practicing multiple perspectives, how well the course materials work, how far students get involved in reflecting on their own learning, in addition to how far they assess their own reflective practices. Such a learner-focused environment will consequently lead to learner empowerment and helps learning best in the future. This view is supported by some researchers (e.g. Mezirow, 1997; Taylar cited in King, 2002 Triscori \& Swartz, 2007). In the instructional context, we critically reflect on " the assumptions we or others make when we learn to solve problems instrumentally or when we are involved in communicative learning (Mezirow, 1997: p. 7)". Mezirow et al. (2000) elaborate this view referring to the frames of reference made because of critical reflection on beliefs, assumptions and values. Frames of reference to them-"may be highly individualistic or shared as a paradigm (p. 20)." 
As it is asserted before, that critical reflection is the main core of transformative learning which in turn is the key feature of adult education, critical reflection does not just involve adults generally thinking and reflecting during practice, but it refers specifically to reflecting back on prior learning experiences under specific circumstances (Mezirow, 1990). Critical reflection here - is broken into a taxonomy according to Mezirow cited in Feldt (2006: p. 4): "(1) critical reflection of assumptions (CRA), which focuses more on instrumental learning (e.g., critiquing a text) through objective reframing with the intent to improve performance; and (2) critical self-reflection of assumptions (CSRA), subjective reframing, which focuses on the psychological and cultural limitations of one's world view."

In teacher education, critical reflection about teaching is important for six reasons identified by Brookfield cited in Glowacki-Dudka \& Barrett (2007: p. 44). It "(1) helps us make informed actions with a better chance of achieving desired outcomes; (2) helps us develop a rational for practice, and the underlying principles behind our practice; (3) helps us keep perspective about limits to our abilities in the classroom; (4) enlivens our classrooms; and (5) increases democratic trust enabling students to feel safe in their own opinions and beliefs."

The assertion of Atherton (2009) that critical reflection is the major objective of adult learning and the real significance of adult learning appears when learners begin to re-evaluate their lives and to re-make them - opens the way to use a different lens through which we filter, engage and interpret the world, then develop adequate and reliable knowledge in a world that is full of ambiguity, change and multi-cultural and social networks and is changing at an ever- accelerating rate. Four strategies are seen to be used for such a purpose. The first strategy constitutes using collaborative work. In order to achieve transformation through collaboration, Triscari \& Swartz (2007) made use of the elements of relationships between partners in learning defined by Soltial (shared goal or purpose - trust - respect and loyalty - personality traits and qualities that are complementary - respect for each 
other - synergy between partners - a valued relationship) in their collaborative project. Through collaboration, partners help each other achieve what they never could have done on their own i.e., merge perspectives, gain commitment, improve relationships and integrate solutions, and create new habits of mind."

Collaboration creation requires stepping beyond the self and one's prior assumptions and dropping boundaries so that the two are seeing as one. It is the spirit of inquiry that is at the root of this creative process. Each partner must be willing to question not only the other partner's thinking and observation, but their own, Garmston cited in Triscari \& Swartz (2007: p. 316)." The process of collaboration requires both partners to move beyond the acquisition of new knowledge and understanding, into questioning of existing assumptions, values and perspectives.

The second strategy might be reflecting on and understanding the habitual action of those who are engaged in critical reflection. Without this step, transformative learning seems difficult to take place. This is because the habitual action is an activity that is performed automatically, or with little conscious thought due to frequent use; understanding constitutes making as of existing knowledge without appraising that knowledge remaining within pre-existing schemes and perspectives; reflection involves critique of assumptions about the content and the process of problem solving, and critical reflection involves the testing of premises.

Adopting a reflective model seems to be the third strategy. As it is quite known that teacher education programs have adults of different social and cultural backgrounds, and of different education levels. Using or adopting a certain model helps identifying those adults/ prospective teachers progress in critical reflective thinking. Lil \& La (2005) - for example - used King \& Kitchner's reflective judgment model (RJM)( to reach that goal. That model involves three platforms of seven stages.

At the first platform, pre-Reflective thinking, "students perceive knowledge as absolute and certain. As a result, they do 
not understand that real problems exist. For which there may not be an absolutely correct answer. They do not use evidence to reason toward a conclusion. Even when they do, their reasoning is not logically connected to the issue being discussed, (p. 223)." At the second platform, Quasi-Reflective thinking, "some problems in the world are acknowledged as real life problems that certain an element of uncertainty. Although they use evidence, quasi reflective thinkers have difficulty drawing a reasoned conclusion. Therefore, knowledge is contextual, and justification is idiosyncratic and context-specific, (p. 226)." At the third platform ${ }_{\llcorner}$Reflective thinking, 'knowledge is not given' but must be actively constructed, and ... Knowledge must be understood in relation to the context in which they were generated. Whereas judgment should be grounded in relevant data, conclusions should remain open to re-evaluation (p. 227)." Central to critical reflection are four activities identified by Brookfield cited in Clark (2008): assumption analysis, contextual awareness, imaginative speculation, and reflective skepticism, certain practical steps in certain conditions and processes are seen to be the fourth strategy to help cause perspective transformation resulting from critical reflection. Clark (2009: p. 7) introduces five main steps namely:

1. An activating event that exposes the limitations of a student's current knowledge/approach;

2. Opportunities for the student to identify and articulate the underlying assumptions in the student's current knowledge/approach;

3. Critical self-reflection as the student considers where these underlying assumptions come from, how these assumptions influenced or limited understanding;

4. Critical discourse with other students and the instructor as the group examines alternative ideas and approaches; and Opportunities to test and apply new perspectives.

To sum, considering some issues raised in the literature view such as the why's behind learning, different ways of knowing, various notions and perspectives about the definitions, phases, significance and requirements of transformative 
learning, critical reflection which is the core of transformative learning and the key characteristic of adult education, it becomes logical to inject critical reflection into teacher education programs, i.e., to shape them with transformative learning. Prospective teachers consequently can accomplish many objectives. Among them are:

1. Being involved actively in and critically on their experiences and those of others, prospective teachers can reframe those experiences and consider alternatives for future applications.

2. New professional knowledge can be constructed due to new insights awakened and perspectives integrated.

3. Professional practice pre-service and afterwards in real situations can be improved when performances are evaluated, ideas and assumptions are tested, strengths and weaknesses are located, actions are rationalized, and then new insights are gained.

4. New teaching skills and problem-solving skills can be acquired since teaching is viewed as a problem-solving situation.

5. Existing beliefs and assumptions about teaching and learning can be triggered, and new ones can be transformed into new contexts.

6. Establishing a safe, supportive, collaborative classroom climate helps foster learners' accountability for their learning and teachers' responsibility for teaching.

\section{The pedagogic Context for Developing Transformative Learning}

Throughout Mezirow's work on transformative learning, one can conclude the ideal conditions implicitly and explicitly set for its full realization and may serve as standards for judging the quality of adult learning. Based on Mezirrow' work, Taylor cited in Tibbitts (2005: p. 105) identified general practices and conditions required for transformative learning: 
1. Ideal learning conditions promote a sense of safety, openness and trust.

2. Effective instructional methods support a learnercentered approach, and promote student autonomy, participation and collaboration.

3. Activities encourage the exploration of personal perspectives, problem-posing and critical reflection.

4. Teachers need to be trusting, empathetic and caring.

5. The environment must support personal self-disclosure.

6. It is essential to discuss and work through emotions and feelings before engaging in critical reflection.

7. Feedback and self-assessment assist the process of transformative learning, as do solitude and self-dialogue.

McGonigal (2005) recommends several conditions and processes that are similar in a way or another to those aforementioned. In order for perspective transformation to happen, McGonigal suggests creating on environment that is featured by the following teaching strategies:

- Presenting activating events.

- Identifying current assumptions.

- Encouraging critical reflection.

- Encouraging critical discourse.

- Giving students an opportunity to test a new paradigm or perspective.

- Fostering intellectual openness.

To the researcher, the pedagogic context for developing transformative learning can be viewed from three lenses or dimensions namely: the participants, the instructor or the educator, and the instructional situation itself. Concerning the participants/learners participating in a situation created by the educator they should have full information; " are free from coercion; have equal opportunity to assume the various roles of discourse (to advance beliefs, challenge, defend, explain, assess evidence, and judge arguments); become critically reflective of 
assumptions; are empathetic and open to other perspectives; are willing to listen and to search for common ground or a synthesis of different points of view; and can make a tentative best judgment to guide action, (Mezirow, 1997: p. 10)." More specifically, learners should engage in group discussions where talk to others help work through beliefs and assumptions, not only for exchanging opinions and ideas or receiving support and encouragement, but also where alternatives are seriously considered. But engagement in a reflective practice should run under the guidance of a tutor as Hunt cited in Stein (2008) recommends. And in order for such practice to be effective, implicit assumptions and practices are to become visible and neither the instructor nor the learner can chart or predict the outcome. Merriam (2004) supports the same idea stating: "For transformative learning to occur, are must be able to critically reflect and engage in rational discourse; both of these activities are characteristic of higher levels of cognitive functioning, ( $p$. 64)."

Another important point is that the willingness of learners to participate in reflective discussions and to generate change in the situation receives much attention from researchers in transformative learning field. Wolfe (2009) - for example - holds the view that transformative learning requires that the students have a vested interest in their own learning process, rather than being "spoon-bed" a bunch of information to memorize or accept. To Wolfe (op. cit.)," the student must be a willing participant, ready to engage in the learning process. The teacher can create the atmosphere in the classroom, but the student must be receptive. Transformative learning causes a change in thinking after digesting information ... The student must make the connections within himself to create this new awareness. Knowledge then becomes a part of the student as he begins to make new associations and own it for himself." Schön cited in Glowacki-Dudka \& Barrett (2007) describes the reflective practice of practitioners when examining their work seeking for improving it through understanding their response to daily situations. He states: " The practitioner allows himself to 
experience surprise, puzzlement, or confusion in a situation which he finds uncertain or unique. He reflects on phenomenon before him, and on the prior understandings which have been implicit in his behavior. He carries out an experiment which serves to generate both a new understanding of the phenomenon and a change in the situation, (p. 43)."

Because engagement in practice (reflective practice in our context), various communities of practice are there, as " a person can (and usually does) belong to multiple communities of practice through a process labeled by Wenger (1998) as multimembership. Essentially, multimember ship involves recognition that each of us is a part of more than one community of practice, and that we normally move between these communities without a conscious sense of doing so.

This view stresses the motion of education in its broadest conception in that "it is a matter of becoming a participant in multiple communities of practice, and of successfully integrating the different transformations that are involved in this process, (Wenger, 1998: p. 4)." Competent membership in a community of practice can be reflected in different ways. Cranton (2002) sees that critical reflection should be taught in teams through modeling where participants are engaged in collaborative critical reflection on experiences. Reflection here is not only a process of building collective knowledge and consensus, but also strong foundations for both transformative learning in the workplace and thriving self-organized teams. It is also a way to discover appropriate forms of matrices because it helps people apply multiple lenses of analysis to their work. To Glowacki-Dudka \& Barrett (2007), the content of developing critical reflection is also believed to be face-to-face classroom environments where collective interactions and reflections take place, multiple perspectives are considered while maintaining an open perspective to achieve a broader context for understanding. Through the examination of beliefs, goals and practice, further insights and understanding are gained, and more consistent actions can be captured and practitioners come to interpret and 
create new knowledge and actions from their ordinary and sometimes extraordinary experiences, the teacher's role - here is to establish a supportive and challenging environment that builds trust and care and facilitates the development of sensitive relationships among learners. Besides, enabling beliefs and modeling-according to D'Amico and Capehart cited in Kerka (2005) - can add more to the teaching of transformation. " Enabling beliefs include instructor's confidence in the ability of adults with low literacy levels to evaluate their own learning and competence, faith in practice as a primary means for improvement in literacy and numeracy, and belief in modeling as critical to facilitating learning behaviors, (p. 3)."

On the other hand, Chudhuri (2007) highlights a set of classroom exercises/peer dialogs like ice-breakers, get acquainted and eye-opener in areas addressing the complexities of relational joining, intimacy, and working with diversity within self and bridging to others. Such exercises are thought to foster transformative learning because as Chudruri (op. cit.) thinks that, "the relationship students develop with each other as they struggle through are much closer, supportive, and enriching then when they compete with each other or are isolated from each other, (p. 93)." Furthermore, the intent participation learning model described by Rogoff et al. cited in Erickson (2007) is applied. Learners engage collaboratively and flexibly in horizontal productive and purposive participations. By this, " responsibilities for learning are shared and the knowledge each member brings contributes to the new learning created by the group, Erickson (2007: p. 142). " The role of the experienced people the instructors - is to guide and to facilitate learners' involvement.

From a psychological view and departing from the premise of the presence of multiple selves within each person, Piper (2005) proposes that unlike the monological self-grounded in the idea of a singular, focused, fully centered and controlling ego, the dialogical self should be oriented toward an awareness of its own multiplicity, i.e., there are many polyphonic others within the 
self/various inner voices with various positions perspectives, frames socially and subjectively constructed when such an awareness is developed, it becomes possible for the subject to engage in dialogue among its various voices promoting selfreflection and critical questioning and consequently developing moral dispositions and conscience. To Piper (op. cit.) " the dialogical model supports the idea of engaging students in activities in which they are encouraged to monitor their own thoughts, feelings, and actions, rather than in activities which perpetuate objective, monological modes of self-thematization, (p. 43)."

As for the instructor, transformative learning is difficult to occur without the key role played by the teacher. In this respect, Dougherity (2005) stresses the role of communities of practice in which learners are engaged in active, conscious sense of doing under the guidance of an expert. He then clarifies the situation stating. "One has become an apprentice, not just to a single master teacher or practitioner, but to a whole community of practitioners either directly or by proxy through a few visible representatives (p. 4)." However such a learning environment should be featured by safe and structured climate to increase learner willingness to share, (Haddock cited in Stein, 2008).

From another point of view, the teacher is to build trust and care and facilitate the development of sensitive relationships among learners, i.e., to create a community of individuals who are as Scott cited in Wikipedia (2009) believes - "united in a shared experience of trying to make meaning of their life experience. "The teacher also serves as a role model by himself demonstrating a willingness to learn and change. In addition, action learning and collaborative inquiry indicated by Yorks and Marsik's work (2009) are both powerful methodologies for facilitating transformative learning. Those who are involved in periodic instruction, reflection and dialog around cultural experiences, critical reassessment of their values, attitudes and frames of reference, critical reflection as a state can consequently facilitate the possibility for transformative learning. 
Although much interest has been devoted to the role of the teacher in transformative learning, Ettling (2006) offers a view stressing the role of ethics for such a process. She sees that the first responsibility of educators is to educate and develop themselves professionally: (1) they have to engage themselves in a conscious, ongoing examination of the appropriateness of methods that are used and the implications of outcomes that are fostered; (2) Real problems are to be put into practice in the classroom; (3) both the teacher and the community of learners should engage in a communal dialogue in a shared endeavor and both are consequently changed through this shared experience; (4) the educator is not to overstate the instructor power in this sort of adult learning situation because students "learn from each other, and then they take it out of the classroom and continue to make sense of what they learn. The important thing is that an educator gives students tools that they can use to live their lives, Hanley cited in Ettling (2006: p. 64)"; (5) The educator should have the attitude of attunement, i.e., be able to listen carefully to what is voiced and unvoiced in the educational context; (6) a transformative curriculum should be "a process not of transmitting what is known but of exploring what is not known, Doll cited in Ettling (2006: p. 62)." Such aspects of the instructor's role in such contents highlight - in the researcher's belief - two important things. First, reflective/transformative learning that develops knowledge takes place in practice-based settings with wise, democratic, and planned apprenticeship which involves experiential learning from the two poles of the situation. Second, active and conscious engaging in real experiences is crucial to deep learning, being involved in making meaning.

With the fact that the components of any situation cannot be easily segregated but for study because of the interdependence and collaborative relationships of the components, the instructional situation for transformative learning should - from the researcher's point of view - be analyzed in order to identify its main features. The generative 
dialog might be the first feature. Gunnlaugson (2007) introduces generative dialog shaped by argumentative discussion that inspires insight and further inquiry, and debate that surfaces the hidden array of positions and perspectives and challenges learners to give adequate reasons for their beliefs. "As an ideal of discourse, debate strengthens our ability to analyze and reflect critically on issues, make reasonable inferences and arguments, and foster an overall willingness to accept the best judgment in the absence of empirical evidence, (p. 169)."

Given learning goals behind engagement in group discussions that include the construction of knowledge - a feature of critical reflection, the core of transformative learningSchwarz et al. (2004) suggest five teacher-guided dialogues for classroom use in order to guide construction of knowledge and consequently faster transformative learning some sort of commitment arises in each type of dialog when people engage in talk together and that commitment has implicit rules governing the talk and interact with the cognitive processes of the participants.

- Grounding dialog is for triggering interest where participants are committed to share common knowledge.

- Prospective dialog is where the commitment is to prepare to learning. And the teacher engages the participants in brainstorming for expressing a position.

- In critical dialog, participants are committed to understand and accommodate divergent viewpoints. The teacher supports argumentation and knowledge construction whereas students share opinions and persuade their peers to.

- Reflective dialog. The participants are committed to integrate and generalize accepted conclusions and arguments activated by the teacher's elicitation.

- In lesson delivery dialog, participants are committed to transmission of knowledge (Schwarz et al, 2004: pp. 170171). 
The third feature might be the disorienting experience or the stressful one where one is confronted with one's inabilities to cope with new demands. Such an experience can spark the process of transformation. Daugherity (2008) stresses that notion stating: "Transformational learning may occur when people are required by circumstances or choice to struggle in areas that challenge them intellectually, emotionally, somatically, socially, morally, or in any combination of these areas. If they successfully navigate the disorientation and distress, incorporating new insights and perspectives into their lives, we can say that transformational learning has taken place, (p. 6)."

Meaningfulness seems to be the fourth feature. This is because transformative learning requires a form of education very different from that commonly associated with children, education that makes learning a meaningful active process, develops autonomous thinking and fosters critically reflective thought and imaginative problem-posing. And the discourse is learner-centered, participatory, and interactive; and it involves group deliberation and group problem solving.

Stressing that any instructional situation needs tools and materials in order to be able to achieve its objective, the best use of the instructional tools, methods and materials in transformative learning situation can constitute the fifth feature. The instructional materials - for example - reflect the real life experiences of the learners and are designed to foster participation in small group discussion, to assess reasons, examine evidence, and arrive at a reflective judgment. Critical incidents as well are advocated by many researchers (e.g. Elliot, 2004; Stein, 2008) as a tool for teaching critical reflection. Elliot (2004) recommends critical incidents to be used for reflection an action (rather than in action) to create researchable questions.

A critical incident as defined by Hannigan cited in Elliot (2004) as one which causes a person to pause and contemplate the events that have occurred to try to give them one meaning. Using a critical incident as a way of reflecting involves the identification of behavior deemed to have been particularly 
helpful or unhelpful in a given situation. But learners are recommended or asked to select critical incidents arising from the practice environment. This selection may be an indicator that they " have the opportunities to change, (Atherton, 2009: p.). Otherwise their critical reflection may simply lead to the conclusion that they are on a " hiding to nothing " and to learned helplessness (op. cit.).

And in response to the notion that student teachers are different and enter the instructional situation with their own varied experiences, beliefs, perspectives and even expectations, what might be better for a certain situation might not in another. Some researchers in transformative learning field suggest some different tools, materials and methods that - in their view - best serve those students in different settings. And it becomes more appropriate for the researcher to note some tools, materials and methods down as follows:

Autobiographical stories (Brookfield, 1995); group discussions focusing on real experiences or posing hypothetical situations, written reports (Clark, 2008); professional development activities (Cranton \& King, 2003); Subject-ObjectInterviews (SOI) (Erickson, 2007); action learning groups (Graham, 1995); action research projects, case and cultural studies, practical experiences, structured curriculum task (Halton \& Smith cited in Clark, 2008); diary keeping or journaling (Heath, 1998; Woodfield \& Lazarus, 1998); reflective learning modules (Hunt, 1996); reflective essays, the Learning Activities Survey free-form journal entries, open inquiry (King, 2002); autobiographical narratives, linguistic autobiographies, research diaries (Leshem \& Traford, 2006); experience and reflection seminars for small teams (Marsick, 1990); storytelling (McDrury \& Alterio, 2000); action research (Thorne \& Qiang, 1998); sketching (Willis, 1999).

Although the group development sequencing of four progressive stages used was in an on-line environment, it is believed that it can be used in traditional settings, face-to-face classroom environments. Because the sequencing is of practical 
application for accessing critical reflection in the classroom, it is briefly described as follows: the forming stage included a testing of boundaries of both interpersonal and task behaviors. The storming stage was characterized by conflict and polarization around interpersonal issues. The norming stage was identified for group cohesiveness, evolving new standards, and adapting new roles. In the performing stage, the groups were engaged reflectively in the class and were ready to accomplish their tasks. Finally, in the adjourning stage, tasks were completed, the group was dissolved, and the roles were terminated after the reflections had been documented.

\section{Preparing the transformative teacher:}

From the transformative perspective, teaching is not transferring knowledge, but creating possibilities for its production and construction. A permanent dynamic interaction should be there between transformative learning as an ongoing personal process and fostering transformative learning in our every day practices. However, there are some reasons behind the absence of transformative learning in educational institutions especially university education. Heaney \& Harton (1990) identify some of them: reflecting without acting, learning without vision, and the dismatch between the vision (if found) and the agenda. Other reasons can be noted down: the ever-changing nature of culture and society that constitutes a challenge for education, teacher different burdens, constraints to transformative learning due to the complexities of teaching and learning acts or to the dominant ideologies. For such reasons and others, transformative learning-as a way of being in which we are engaged in critical reflection for change is relatively rare within settings of adult education (Dirkx, 2009).

The researcher holds the claim that most teachers even at the university level are teaching to the requirements of tests although education in the 21 century has come to reflect product-based and results-oriented societies. This means that teachers with expertise and knowledge highlighting the classroom know-how and considering the emotional and cultural 
needs of students - are demanded to play their role in helping students to rethink, to reframe, and (re)construct knowledge, understand themselves and the world in which we all live.

It would be necessary - in this respect - to prepare the teacher who examines the theoretical traditions and taken-forgranted practices since the intent is to encourage self-reflective ways of thinking and to provide frameworks of rethinking teaching and learning i.e., to boost and maintain a critical reflective mind. But one of the most important challenges for keeping a reflective mind - according to Traverso \& Yépez (2008: p. 168) "is to care not only for our individual growth, but also for the socio-cultural context that encourages intellectual openness; meaningful, genuine relationships; as well as social justice, and overcoming every kind of social exclusion."

Thus, the proposed framework of a transformative teacher in the community of knowledge might have the following procedures for its implementation.

B. Specify instructional goals and objectives based on four scales: Habitual Action, Understanding, Reflection and critical reflection.

C. Design and implement instruction that is consistent with goals and objectives taking into consideration that self-directed as well as reflective transformative learning is encouraged by (i) posing real experiences and hypothetical situations to encourage reflection in general and critical reflection in particular; (ii) providing probing questions that cause the learner to continue to think about the topic; (iii) encouraging peer feedback that is powerful when it is used interactively in interpersonal dialog; (iv) helping students seek alternatives by one or more of the following: view from various perspectives, seek the framework and the theoretical basis underlying rational of behaviors, methods, techniques ... etc., compare and contrast, put into 
different or varied contexts- ask 'what if ...?', consider consequences.

The educator may employ different reflective, and collaborative learning activities with his students. These activities include engaging in social learning behaviors (inviting, assisting, directing, tutoring, modeling), negotiation (consensus building, compromise) and feedback (information checking, correcting). This peer-assisted learning helps move practitioners towards independent learning.

The educator can also prepare various types of classroom materials that are suitable for the time available and the student teachers' intellectual and linguistic levels, and consistent with the goals and objectives of the program. Some of the materials are seen to be teaching practice notes, classroom talk, conversation about the practicum, lesson plans, personal diaries, role plays, storytelling, case studies, reflective essays, critical incidents, assigned readings... etc.

\section{References}

Atherton; James (2009). Learning and Teaching; Critical Reflection. Available from: www.learningand teaching.info/learning/critical.htm(Sept.7,2009).

Belenky, Mary F. \& Stanton, Ann V. (2009). Transformative Learning as Relational, or connected learning. Available from: www. perseubooksgroup.com/basic/author_detail.Jsp? Id= 269930 (October 2, 2009).

Brookfield, S. (1995). Becoming a Critically Reflective Teacher. San Francisco: Jossey-Bass.

Brookfield, S. (1998). Critically Reflective Practice. Journal of continuing Education in the Health Professions. Vol. 16, No. 4. (Fall 1998), pp. 162-184.

Choudhuri, Devika D. (2007). Fostering Parallels of Relationship and Meaning Making towards Transformative Learning. 
Paper Presented at the Seventh International Transformative

Learning Conference, Transformative Learning: Issues of

Difference and Diversity, October 24-26, 2007, Aluquerque,

New Mexico, pp. 89-94.

Clark, M. (2008). Critical Reflection. Available from: Personal-

mail: donclark@nulink.com (October 10, 2008).

Cranton, Particia \& King, Kathleen P. (2003). Transformative

Learning as a Professional Development Goal. New

Directions for Adults and Continuing Education, No, 98,

Summer 2003, pp. 31-37.

Cranton, Particia (2002). Teaching for Transformation. In J. M.

Ross-Gordon (Ed.), New Directions for Adult and Continuing

Education: No. 93. contemporary View points on teaching

Adults Effectively (pp. 63-71). San Francisco, CA: Jossey-

Bass.

Daugherity, Frank (2008). Transformational Learning.

Daugherity Blog (August 23, 2008).

Davis, Ann (2007). Transformative Relational Dialogue Activities.

Paper Presented at the Seventh International Transformative

Learning Conference, Transformative Learning: Issues of

Difference and Diversity, pp. 376-381.

Dirkx, John (2009). Transformative Learning Theory: The Way of

Logos. Available from. Available from:

http://john.dirkx.met.

Dirkx, John M. (2009). Transformative Learning theory in the

Practice of Adult Education: An Overview. Available from: http://john.dirkx.met (June 20, 2009).

Donovan, Loretta L.; Meyer, Susan R. \& Fitzgerald, Stephen p. (2007). Transformative Learning and Appreciative Inquiry:

A more Perfect Union for Deep Organizational Change. Academy of Management Proceedings, Philadelphia, August 2007.

Doyle, Clar (2008). Dancing Toward Transformation: Mapping a pedagogical site. In Narrating Transformative Learning in Education, Morgan Gardner \& Ursula Kelly (Editors), Palgrave Macmillan, New York. (pp. 145-156). 
Elliot, Malcolm (2004). Reflective thinking: Turning a Critical Incident into a Topic for Research. Department of Nursing, University of Wallongong, New South Wales, Australia.

Erickson, Diane (2007). Discourse: The Individual and the Social Interface in Transformative learning Paper Presented at the Seventh International Transformative Learning Conference, Transformative Learning: Issues of Difference and Diversity, October 24-26, 2007, Aluquerque, New Mexico, pp. 139143.

Erickson, Diane M. (2007). A Developmental Re-forming of the Phases of Meaning in Transformational Learning. Adult Education Quarterly, Vol. 58, No. 1, Nov. 2007, pp. 61-80.

Ettling, Dorothy (2008). Ethical Demands of Transformative Learning. New Directions for Adult and Continuing Education, No. 109, Spring 2006, pp. 59-67.

Foster, E. (1997). Transformative Learning in Adult Second Language Learning. New Directions for Adult and Continuing Education, Vol. 74, pp. 33-40.

Feldt, San (2005). Transformative Learning Theory: An overview.

Personal-mail: dsanfeldt@uwe.ac.uk. (July 5, 2007).

Gardner, Morgan (2008). Transformative Learning as a Pedagogy of Movement. In Narrating Transformative Learning in Education, Morgan Gardner \& Ursula Kelly (editors), Palgrave Macmillan, New York., pp. 11-30.

Glisczinski, Dainel J. (2007). Transformative Higher Education: A

Meaningful Degree of Understanding. Journal of

Transformative Education, Vol. 5, No. 4, pp. 317-328.

Glowack-Dudka, Michelle \& Barnett, Nicole (2007). Connecting Critical Reflection and Group Development in Online Adult Education Classroom. International Journal of Teaching and Learning in Higher Education, Vol. 19, No. 1, pp. 43-52.

Graham, I. W. (1995): Reflective Practice: Using the Action Learning Group Mechanism. Nurse Education Today, Vol. 15, No. 1 (Feb. 1995), pp. 2832.

Gunnlaugson, Olen (2007). Dialogue Education: A Response to Working with Diverse Perspectives in the Post-Secondary classroom. Paper Presented at the Seventh International 
Transformative Learning Conference, Transformative Learning: Issues of Difference and Diversity, October 24-26, 2007, Aluquerque, New Mexico pp. 168-173.

Hallet, Michael; Roberts, Rick \& Jaffee, David (2009). CommunityBased Transformational Learning. Available from www.unf.edu/outreach/survey.html(March 21, 2009).

Heath, H. (1998). Keeping a Reflective Practice Diary: A Practical Guide. Nurse Education Today, Vol. 18, No. 7 (Oct. 1998), pp. 595-598.

Hoban, Garry (2000). Using a Reflective Framework to Study Teaching-Learning Relationship. Reflective Practice, Vol. 1, No. 2, pp. 165-182.

Holistic Education Network (2005). Transformative learning, Holistic Education Network of Tasmania, Australia. Available from: www.adminathent.org (July 3, 2009).

Hunt, C. (1996). Function, Fascination, and Facilitation of Reflective Practice in Continuing Professional Education. In Diversity and Development: Futures in the Education of Adults. Proceedings of the 26 the Annual conference, Leeds, England, July 2-4, 1996. Standing Conference on University Teaching and Research in the Education of Adults, 1996. (ED 398408).

IATUL (2009). Information Transformation Learning. Available from: www.iatul.org (July 20, 2009).

Imel, Susan (1998): Teaching Critical Reflection: Trends and Issues Alert. Available from: www.calproanline.org/ERIC/textonly/docgen.asp?tlol=tia\&ID=125(July 31,2009).

Jarvis, Peter; Holtford, John \& Griffin, Colin (2003). The Theory and Practice of Learning ( $2^{\text {nd }}$ edition), Kogan Page, London. Kerka, Sandra (2005). Applying Adult learning Theory: Selfdirected Learning and Transformational Learning in the Classroom. California Adult Education, Research Digest No. 3.

King, K. P. (2000). The Adult ESL Experience: Facilitating Perspective Transformation in the Classroom. Adult Basic Education, Vol. 10, No. 2, pp. 69-89. 
King, Kathleen P. (2002). Educational Technology Professional Development as Transformative Learning Opportunities. Computers and Education, Vol. 39, pp. 283-297.

Leshem, Shosh \& Trafford, Vernon N. (2006). Stories as Mirrors: Reflective Practice in Teaching and Learning. Reflective Practice, Vol. 7, No. 1, February 2006, pp. 9-27.

Hughes, Mark \& Heycox (2005). Promoting Reflective Practice with Older People: Learning and Teaching Strategies. Australian Social Work, Vol. 58, No. 4, December 2005, pp. 344-356.

Li, Xin \& Lal, Shirly (2005). Critical Reflective Thinking through Service-learning in Multicultural Teacher Education. Intercultural Education, Vol. 16, no. 3, (August 2005), pp. 217-234.

Lucas, Ursula and Tan, Phaik Leng (2006). Assessing Level of Reflective Thinking: The Evaluation of an Instrument for Use within Accounting and Business Education. In The $1^{\text {st }}$ Pedagogic Research in Higher Education conference, Liverpool Hope University, 2-3 May, (2006).

McDrury, Janice \& Alterio, Maxine (2000). Achieving Reflective

Learning Using Storytelling Pathways. Innovations in Education and Teaching International, Vol. 38, No. 1, pp. 6373.

McGonigal, Kelly (2005): Teaching for Transformation: From Learning Theory to Teaching Strategies. Speaking of Teaching Newsletter, Vol. 14, No. 2, Spring 2005.

McGregor, Sue L. (2008). Transformative Education: Grief and Growth. In Narrating Transformative Learning in Education, Morgan Gardner \& Ursula Kelly (editors), Palgrave Macmillan, New York (pp. 51-73).

Merriam, S B., \& Caffarella, R. S. (1999). Learning in Adulthood: A comprehensive Guide (2nd edition). San Francisco: JosseyBass.

Merriam, Sharan B. (2004). The Role of Cognitive Development in Mezirow's Transformational Learning Theory. Adult Education Quarterly, Vol. 55, No. 1, 60-68. 
Mezirow, Jack (1997). Transformative Learning: Theory to Practice. New Directions for Adult and Continuing Education, No. 74, pp. 5-12.

Mezirow, Jack \& Associates (1990). Fostering Critical Reflection in Adulthood: A Guide to Transformative and Emancipatory Learning. San Francisco: Jossey-Bass.

Mezirow, Jack (1990). How Critical Reflection Triggers Transformative Learning. In Fostering Critical Reflection In Adulthood: A Guide to Transformative and Emancipatory Learning, (Jack Mezirow and Associates Eds.), San Francisco: Jossey-Bass, pp. 1-20.

Mezirow, Jack (2000). Learning as Transformation: Critical Perspectives on a Theory of Progress. San Francisco: Jossey Bass.

Morrison, Connice (2008). Critical Autobiography for

Transformative Learning: Gaining a Perspective on Perspective. In Narrating Transformative Learning in Education, Morgan Gardner \& Ursula Kelly (Eds.), Palgrave Macmillan, New York (pp. 111-126).

Nelson, Zoe (2007). Transformative Learning Theory. Available from http://amps-tools.mit.edu/tmoperfology/archiaes (June 23, 2008).

Piper, David (2004). Moral Development, Transformative Learning, and the Dialogical Self, Westminster Studies in Education, Vol. 27, No. 1, April 2004, pp. 43-55.

Stain, David (2008). Teaching Critical Reflection. Available from: http://ericacve.org (Sept. 9, 2009).

Taylor, Edward w. (1998) The Theory and Practice of Transformative Learning: A critical Review. Information Series No. 374. Columbus: ERIC Clearinghouse on Adult, Career, and Vocational Education, center on Education and Training for Employment, Collage of Education, the Ohio State University.

Thorne, Christine \& Qiang, Wang (1998). Action Research in Language Teacher Education. ELT Journal, Vol. 52, No. 4, pp. 254-262. 
Tibbitts, Felisa (2005). Transformative Learning and Human Rights Education: Taking a Closer Look. Intercultural Education, Vol. 16, No. 2, May 2005, pp. 107-113.

Traverso-Yépez, Martha (2008). Examining Transformative Learning Amidst the Challenges of Self-Reflection. In Narrating Transformative Learning in Education, Morgan Gardner \& Ursula Kelly (editors), Palgrave Macmillan, New York pp. 157-171.

Triscari, Jacqlyn \& Swartz, Ann (2007). Transformation through Collaboration. Paper Presented at the Seventh International Transformative Learning Conference, Transformative Learning: Issues of Difference and Diversity, October 24-26, 2007, Aluquerque, New Mexico pp. 316-320.

Wallace, M.J. (1991). Training Foreign Language Teachers: A Reflective Approach. Cambridge: Cambridge University press.

Wenger, E. (2003). Communities of Practice: A Brief Introduction : Available from: http://ewenger.com/theory/ index.htm (October 10,2007).

Wolfe, Cindy (2009). Mezirow's Transformational Learning Theory. Available from: www.associatedcontent.com/ article/158463/mezirovs-transformational_learning-html (March31,2009).

Wikipedia (2009). Transformative Learning. Wikipedia, the Free Encydopedia. Available from:

http://en.wikipedia.org/wiki/Transformative-learning (May 5, 2009).

Williamson, A. (1997). Reflection in Adult learning with Particular Reference to learning-in-Action. Australian Journal of Adult and Community Education, Vol. 37, No. 2 (July, 1997), pp. 93-99.

Willis, P. (1999). Looking for What It's Really Like: Phenomenology in Reflective Practice. Studies in Continuing Education, Vol. 21, No. 1, pp. 91-112.

Woodfield, Helen \& Lazarus, Elisabeth (1998). Diaries: A Reflective tool on an INSET language course. ELT Journal, Vol. 52, No. 4, pp. 315-322. 
Yorks, Lye \& Marsick, Victoria J. (2009). Organizational Learning. Available from: http://transformativelearningtheory com/ orgLearning.html (June 20, 2009).

Zeichner, Kenneth M. (1993): Traditions of Practice in U.S. Preservice Teacher Education Program. Teaching and Teacher Education, Vol. a, No. 1, pp. 1-13. 
